\title{
Role of Community Acceptance in Sustainable Bioenergy Projects in India
}

\begin{abstract}
:
Community acceptance has been identified as one of the key requirements for a sustainable bioenergy project. However less attention has been paid to this aspect from developing nations and small projects perspective. Therefore this research examines the role of community acceptance for sustainable small scale bioenergy projects in India. While addressing the aim, this work identifies influence of community over bioenergy projects, major concerns of communities regarding bioenergy projects and factors influencing perceptions of communities about bioenergy projects. The empirical research was carried out on four bioenergy companies in India as case studies. It has been identified that communities have significant influence over bioenergy projects in India. Local air pollution, inappropriate storage of by-products and credibility of developer are identified as some of the important concerns. Local energy needs, benefits to community from bioenergy companies, level of trust on company and relationship between company and the community are some of the prime factors which influence community's perception on bioenergy projects. This research sheds light on important aspects related to community acceptance of bioenergy projects, and this information would help practitioners in understanding the community perceptions and take appropriate actions to satisfy them.
\end{abstract}

\section{Highlights:}

- Local communities' negative perception about bioenergy projects, impact its operation.

- We identify concerns of local community regarding bioenergy projects in India.

- Air pollution from bioenergy plants is a major concern for the local community.

- We identify factors influencing perception of communities about bioenergy projects.

- Local energy availability influences community's perception of bioenergy plants.

Keywords: Community Acceptance; Bioenergy; Public Perception

Acknowledgments: Authors thank financial support from DST, India and RC, UK under Science Bridge project funding. 


\section{Introduction}

Renewable energy sources were the first to be accessed by mankind for fulfilling their simple daily needs and running basic machines. In fact controlled wood fire can be considered as one of the first steps in our advancement. There are number of advantages in using renewable energy. It is local, thus protecting the country from foreign reliance and fluctuating prices of the fossil fuel resources. The most important advantage is of saving the environment. Still, in the era of fossil fuel based industrialization share of renewable energy dwindled to a few percent. For example, in 2012 renewable energy accounted for $10.7 \%$, $6.5 \%, 3.1 \%, 3.8 \%$ and $4.7 \%$ of the total primary energy consumption in industrialized countries such as China, USA, Russia, Japan and UK respectively (Enerdata, 2013a). Such a low share of renewable energy shows that a large share of energy demand is met by fossil fuels, which leads to global warming.

The total energy consumption and share of renewable energy in the total primary energy consumption in India during 2012 were 774 million tonnes of oil equivalent (Mtoe) (Enerdata, 2013b) and 24.3\% (Enerdata, 2013a) respectively. When compared to other developed nations India's energy consumption per capita is low and share of renewable energy is higher. However, in 2010 , the overall electrification rate in India was only $75 \%$, with a share of $94 \%$ and $67 \%$ of electrification in urban and rural areas respectively (IEA \& OECD, 2012). In addition to that, in accounting year 2010-11, in India the official electricity supply shortage during normal and peak loads were $8.5 \%$ and $9.8 \%$ respectively (Central Electricity Authority, 2012). Also, India is currently in the process of transformation from a developing nation to a developed nation through economical growth. Energy is one of the important requirements for growth and development (IEA, 2002), and the projected growth of India will lead to a further increase in energy demand. Therefore, in the context of lack of access to modern energy for considerable amount of population, increasing energy demand and heavy dependence on imported fossil fuel resources and carbon footprints left by their use, India is looking to increase its utilization of renewable energy sources such as biomass, solar, wind and hydropower.

It should be noted that in most of the developing countries, biomass continues to be one of the important source for fulfilling local household energy needs. Biomass is mainly used in these households for cooking, space heating and water heating. For example, the percentage of various fuels used for cooking in India based on the national census 2011 
data, is given in Figure 1 . These data show that nearly $67 \%$ of all households in India use any one form of bioenergy for cooking, whereas in rural areas approximately $85 \%$ of the households use bioenergy for cooking (Deloitte, 2013). However, the exposure to indoor pollution and toxic by-products of combustion due to traditional biomass use in households, affects the health of women and children particularly (IEA \& OECD, 2006; South Centre, 2008). Keeping the above mentioned issues such as low rate of electrification in rural areas of India and health issues arising from traditional biomass use and the availability of biomass in mind, the Indian government's ministry of new and renewable energy (MNRE) is initiating "National Bioenergy Mission", which will further support the uptake of bioenergy in India (Jain et al., 2011; Shweta, 2012). In particular small scale bioenergy systems have been increasingly promoted in Indian context because of their decentralised energy production capability, significant benefits to community and its ability to utilise small quantity of biomass resources available in the local area (Hiremath et al., 2010; Kumar et al., 2009). Hence given its need, importance and potential, focus of this paper is on small scale biomass based energy production.

\section{Figure 1: Various Fuels Used for Cooking in India}

For electric power generation through biomass, availability of appropriate fuels in adequate quantity, mature technologies that match the demand and sustainable business case are necessary (Camerata \& Bansal, 2011; Ravindranath \& Rao, 2011). Nevertheless studies have identified that in some cases even when technology and feedstock was available and business case for projects was in place, still the bioenergy projects faced resistance due to opposition from the communities (Rohracher et al., 2004; Rösch \& Kaltschmitt, 1999; Walter \& Gutscher, 2011). If the concerns of communities are not properly addressed it can create a bad perception and insufficient acceptance of bioenergy projects among the communities (Harrison et al., 2011; Rösch \& Kaltschmitt, 1999). Hence community acceptance is identified as one of the critical success factors for bioenergy sector in the developed world (Blumer et al., 2013; Buchholz et al., 2009; Cherni et al., 2007; Roos et al., 1999; Rösch \& Kaltschmitt, 1999; Thornley et al., 2009; Walter \& Gutscher, 2011; Wegener \& Kelly, 2008; Wright, 2006). 
All the studies reviewed during this work pertain to medium to large size plants. Some of these studies state that small scale bioenergy plants could be viewed positively by local communities (Dockerty et al., 2012; Rohracher et al., 2004; Upham, 2006; Walter \& Gutscher, 2011) and this can even help to create a positive image about the medium or large applications as well (Rohracher et al., 2004). In small scale bioenergy systems, local communities can be a highly dominant stakeholder group because they can hold multiple roles in the project such as energy consumers and biomass suppliers. Therefore given the scope for small scale bioenergy systems and limited research in this area, there is a need for further investigations on the role of community in this sector. In addition to that Walter and Gutscher (2011) and Upham (2006) argue that local context has a huge influence over public perceptions towards bioenergy projects. Level of energy security can be one of the important contextual factors. Therefore, perceptions of community towards bioenergy projects under energy deprived conditions as in some parts of India, can be significantly different from that in other developed countries and such a difference provides an interesting setting to study.

The significant role of community in sustainable bioenergy projects in India has been recognised in the following studies. Somashekhar et al. (2000) studied two small scale biomass cases in India both with the capacity of $20 \mathrm{KW}$, where focus of research was on technical, operational and managerial feasibility and sustainability impact of the projects. Study by Ravindranath et al. (2004) was an in-depth analysis of one of the two cases examined in Somashekhar et al. (2000) looking at technical, sustainability and management related issues and impacts during 14 years of its operation. In both of these studies they have analysed market acceptance of the projects by the community as they were the consumers and highlighted the significance of community acceptance for success of the projects. Rao and Ravindranath (2002) have analysed the policy barriers to the adoption of bioenergy systems in India and one of their suggestions to overcome the barriers identified is to enable and increase community participation in decision making. Romijn et al. (2010) investigated suitability of strategic niche management framework in south Asian context by applying it to four biomass energy projects in rural India. They have also identified issues related to the village communities as one of the important management problems for bioenergy projects. However even when the above mentioned studies have recognised the importance of community acceptance for a sustainable bioenergy projects in India, 
literature investigating concerns of the community and factors influencing the community perception is limited.

Given the inadequate research in small scale category, significant differences in the context when compared to other studies from the developed nations and lack of research in the Indian context, this study was undertaken on the role of community acceptance for a sustainable small scale bioenergy projects in India. The following three research questions in this work, what is the influence of community over bioenergy projects in India; what are the major concerns of communities regarding bioenergy projects in India and what are the factors influencing communities' perception about bioenergy projects.

This research has two important contributions to the literature on community acceptance in bioenergy sector. Firstly, knowledge in the field has been advanced through synthesis of literature on communities concerns and factors influencing the communities' acceptance. Secondly, the empirical findings in this research have contributed to new insights from developing countries and small scale bioenergy industries' perspective. This research can help the bioenergy practitioners in understanding the role of a community for a sustainable project which in turn can guide them towards effective relationship building with them.

In the next section of this paper we discuss the research methodology adopted, followed by review of literature on related theories and synthesized themes on the community's concerns and factors influencing the community acceptance respectively. The section on data collection and findings of the empirical case studies follows and discussion and conclusion are presented after that.

\section{Methodology}

Figure 2: Research Design

This research had two main phases as shown in the research design, Figure 2 . In the first phase literature was reviewed to address three purposes namely, to identify research gap, to identify relevant theories and to identify themes on the community's concerns and the factors influencing community acceptance in bioenergy sector. The research gap has already been discussed in the previous section. Other two components of literature review 
phase are presented in the next sections. The most appropriate theoretical lens has been selected after careful examination of different theories related to the research questions. The key themes have been identified by integrating findings of multiple studies by using 'thematic synthesis' approach and these themes developed are 'descriptive themes' based on the primary studies (Thomas \& Harden, 2008). In order to organize the results of thematic synthesis coherently matrix display approach has been used (Miles \& Huberman, 1994).

Following the literature review, empirical research was conducted in India. Multiple case studies is a suitable research strategy for exploring relevance of a phenomena and building a theory (Voss et al., 2002). Therefore in this research, multiple case studies were undertaken to understand influence of the communities over the projects and to identify the key community concerns and factors influencing the community perceptions about small scale bioenergy projects.

Relevance of case study company to the research questions raised and feasibility to carry out and generalise the research are some of the important aspects considered in selecting appropriate cases (Miles \& Huberman, 1994). Purposive sampling approach has been used to select cases based on a set of criteria (Voss et al., 2002; Yin, 1994). In this study two significant characteristics of bioenergy systems considered were bioenergy plant output type and size of the plant. In order to cover the widely used bioenergy systems in India, we considered the plants producing heat, power and combined heat and power (CHP). The study focused on small scale bioenergy sector because of the research gap in this segment and its growing demand, significant benefits to community and emerging role in Indian context (Hiremath et al., 2010; Hiremath et al., 2009; Kumar et al., 2009; South Centre, 2008). Small scale bioenergy systems, in the Indian context is considered to be less than 2MW capacity (Jain et al., 2011). This is the size of the plant considered in this study. Four case study companies were selected based on these criteria.

In-depth interviews and secondary documents were used to collect data from the selected four sample cases. Semi structured interviews were conducted with appropriate members of the case study company such as project manager, project engineer, research scientist and management team member. The interviews were focused on community influence over the company, concerns of the community, how the company managed community concerns, relationship between the company and the community and 
contextual information about community and company. The documents relevant to the study were also collected from the case study companies, which were used to triangulate the information.

The data collected was analyzed using thematic analysis, where themes for coding were developed using a hybrid inductive and deductive approach (Fereday \& MuirCochrane, 2008; Joffe \& Yardley, 2004). The themes identified during the literature review phase in this research were used as the codes during deductive thematic analysis. Both deductive and inductive codes identified with in the case study companies are then analyzed and categorized using the relevant theories recognized during the Phase 1 . The results of empirical study are presented using a case ordered meta-matrix display, which helps to recognize differences across the cases easily (Miles \& Huberman, 1994).

\section{Theoretical Background}

Taking stakeholders' perspective into account is very important in bioenergy sector (Halder et al., 2012; Painuly, 2001; Peelle, 2000, 2001; Qu et al., 2012). Lack of involvement of stakeholders can misplace the priorities in decision making (Painuly, 2001), restrict practical application of the system (Mitchell, 2000, p.274) and success of the system (Ravindranath \& Balachandra, 2009). Freeman (1984, p. 46) defines stakeholders as "any group or individual who can affect or is affected by the achievement of the organization's objectives." Customers, employees, local communities, suppliers and distributors, shareholders, competitors, government and academics are identified as some of the important groups of stakeholders for a business (Friedman \& Miles, 2006). However, list of relevant and important stakeholders for a business is defined by the nature and context of the project.

In the context of bioenergy projects local community is an important stakeholder group because community acceptance is a major challenge for bioenergy projects and this can severely impact on sustainability of the industry (Khan, 2005; Peelle, 2000, 2001; Plate et al., 2010). It is important to recognize that although the terms "community" and "stakeholder" are sometimes used as alternates, they are not the same. Harvey and Brereton (2005, p. 1) state that from mining industry's perspective the word community is applicable "to the inhabitants of immediate and surrounding areas who are affected in some way by a company's activities; these effects may be economic and social as well as 
environmental in nature." This definition can also be applied to bioenergy sector due to similarities in the nature of impact between the two sectors; even though the level of impact is different.

The concept of sustainability is defined very vaguely in the literature, and this has led to lot of confusion and numerous definitions of this concept in various fields such as business management (Gallopín, 2003; Ivory \& MacKay, 2012). In order to summarise basic elements of this concept, Ivory and MacKay (2012) explored the evolution of corporate sustainability and have critically reviewed the literature. They have concluded that corporate sustainability can be classified into two categories namely 'sustainability business' and 'sustainable business'. "A 'sustainability business' focuses on the business contribution to global SD [sustainable development]; while a 'sustainable business' focuses on the business' own sustainable development: that is its own survival and success" (Ivory \& MacKay, 2012, p. 1). One of the very famous sustainability approach considered in the business world is triple bottom line (TBL) approach (economic, environmental and social dimensions) (Elkington, 1997, 1998), this approach falls under 'sustainability business' category as it is concerned about the global sustainable development. However, in this paper communities influence on bioenergy projects and its survival is studied, and this falls under the 'sustainable business' category. Such a focus of the business for its own sustainable development is also termed as 'organisational sustainability' (Garvare \& Johansson, 2010; Johansson, 2008). Therefore, taking the above stated definition into account, sustainable bioenergy project can be defined as the project that focuses on its own survival. One of the most important necessities for a business survival (organisational sustainability) is profit, which depends on various factors such as license to operate, continuity of operation, market demand and raw material supply.

Porter and Kramer (2006) argue that business and society are interdependent and therefore to attain the long term prosperity of both, 'shared value' principles must underpin both the business decisions and social policies. They also classify the points of intersection between business and society into two categories namely inside-out linkages and outside-in linkages. Inside-out linkages are the points of intersection between both where the business operations impinges on the society. The point of intersections where the external social conditions influences the business is termed as outside-in linkages (Porter \& Kramer, 2006). The community acceptance of a project is an outside-in linkage that can influence the 
survival of the business. However this outside-in intersection is dependent on concerns of the community related to business impact (inside-out linkage) and other perception influencing factors. Therefore in this research we have also examined about these driving forces behind community acceptance.

There are three different dimensions of social acceptance, namely socio-political acceptance, community acceptance and market acceptance (Alasti, 2011; Wüstenhagen et al., 2007). The socio-political acceptance is the acceptance of technologies by general public, key stakeholders and policy makers. Public awareness has been identified as the primary enabler for adoption of renewable energy technologies in India (Eswarlal et al., 2011a; Eswarlal et al., 2011b), which signifies the importance of socio-political acceptance in the given context. The market acceptance is adoption of technology by consumers, investors, suppliers and other market players. Community acceptance relates to acceptance of the project by local stakeholders, the community specifically. These dimensions of social acceptance are not completely separated; rather they are interconnected where they influence one another. Therefore, while in this research the focus is on the community acceptance dimension of social acceptance, interaction with other two dimensions also needs to be taken into account.

Wüstenhagen et al. (2007) have identified that community acceptance of a renewable energy project can be influenced by factors related to three categories namely distributional justice, procedural justice and trust. Distributive and procedural justice theories were also used by Walter and Gutscher (2011) in their study to explain public acceptance of wind energy and bioenergy projects in Europe. The distributional justice is about sharing of costs and benefits. Fairness of decision making process and participation and involvement of the stakeholders are associated with the procedural justice. Believing the investors' information and intentions is related to the trust. These categories are applied in empirical research of this work to provide practical and convenient understanding of the data.

\section{Themes from the Literature}

Literature search related to community acceptance of bioenergy projects identified 15 published works dating from 2002 to 2012 . However, these published works in total are related to 8 different studies. Therefore for a better understanding during the process of 
synthesis the 15 published works are combined into related studies and stated using study number. All these studies are related to developed world. This reinforces the research gap identified i.e. inadequate studies related to the developing countries. The study number, the reference of the relevant published works and the information about the study are given in the Table 1 below.

\section{Table 1: List of Studies}

The important concerns of community related to the bioenergy projects, reported in the literature are presented in Table 2. The important concerns mentioned in the studies stated above are synthesised into a list of concerns and the type of community concern mentioned in a particular study is shown using a ' $\checkmark$ ' mark in appropriate study number columns. For clarity and ease of understanding, the list of concerns are categorised based on the classification system used by Upreti (2004). The concerns are classified based on issues related to siting, emissions and health hazards, transport, environmental / ecological effects, landscape and agriculture, economic effects and others.

\section{Table 2: List of Concerns of the Community}

The concerns are diverse and vary between projects mainly due to context and other factors which influence perception of the community that in turn impact on their concerns. Even general public perception about bioenergy is influenced by various things such as lack of understanding and knowledge about the industry (Roos et al., 1999; Rösch \& Kaltschmitt, 1999; Wright, 2006), prejudice (Rösch \& Kaltschmitt, 1999), worry about possible negative impacts, such as security of food supply and biodiversity (Lewandowski \& Faaij, 2006), and trends towards cleaner production technology and waste minimisation (Hooper \& Li, 1996). However community will be more intolerant if the industry is going to be near to their home. Reaction of those in immediate vicinity would be significantly different from the view of the general public. A list of factors which could influence the community's acceptance is developed through literature review and presented in Table 3.

Table 3: List of Factors Influencing the Community Acceptance 
The Table 2 and Table 3 provide list of concerns and factors respectively. Both the findings are not prioritized in any order or quantification based on number of occurrences as purpose of this review is to synthesize all the relevant concerns of community and the factors influencing community acceptance of the project. These findings are a great source of compiled information related to community acceptance in the bioenergy sector. This will be used to analyze data collected from the case studies in the following sections. Detailed discussions of individual aspects (concerns and factors) are not within the scope of this papers this can be referred in the relevant studies given in Table 1.

\section{Data Collection}

Four case studies selected based on the criteria mentioned above are briefly described below. The important criteria of the cases are given in Table 4.

\section{Table 4: Details of the Case Studies}

\subsection{Case $A$}

The Case $\mathrm{A}$ is a demonstration plant setup in the state of Karnataka, India with funding from international organizations and government bodies. The particular project location was selected for a number of reasons such as, "over $40 \%$ of rural households in the district did not have access to electricity", the region possessed over " 400,000 hectares of waste land (comprising nearly $34 \%$ of its total areas)" and availability of alternative biomass resources from coconut and mulberry plantations in the region (Project Document $A, 2013$ ). The main objective behind this project was to reduce "carbon dioxide emissions through promotion of bioenergy as a viable and sustainable option to meet the rural energy service needs in India" (Project Document A, 2013). The plant is operated by a public body under the Government of Karnataka, India. It was commissioned in 2007. Documents, direct observation and 3 interviews were source of data for analyzing this case. In this case company, gasifier technology is used with a total installed capacity of $1 \mathrm{MW}$ but it is spilt into five small modular units' setup at 3 different locations in a cluster of 24 villages. Size of the modular units ranges from $300 \mathrm{KW}$ to $100 \mathrm{KW}$. Raw material used is woody biomass from the forest (forestry residues) and plantations on the community lands. The power plant 
generated electricity and at the time of visit during January 2012, it was supplying it to the grid. But there were plans to convert into an off-grid supply system to supply the nearby villages.

The project does not face any known community conflicts because from very beginning of the project, engagement with the community and other stakeholders was undertaken since one of the important objectives of the project was capacity building of the local communities. In order to involve local stakeholders in decision making process and to provide them more control and opportunities for economic growth local institutional structures have been created, namely Village Bio Energy Management Committees (VBEMC) and Village Forest Committees (VFC). VBEMC facilitates the involvement of village community in decision making process and VFC is primarily tasked to grow biomass to supply the units. In order to empower the community further other activities such as supporting women self help programs, skills training for local people and setting up participatory irrigation management system are undertaken. Also, the workforce is recruited from the local community, which provided lots of new jobs in the community.

\subsection{Case $B$}

The Case B is about a plant in rural Bihar in India. The Case B is a success story of an organization which now has more than 40 bioenergy plants in rural India. The project initially started as a charity and due to success of the idea and potential to electrify rural India it moved from a demonstration model to a sustainable social enterprise. Interview and documents were the source of the data for this case. The project was setup in a village which never had access to electricity or any grid connection and the aim of the project was, "to provide clean electric lighting to the households in $\operatorname{xxxxx~(the~village)~at~a~rate~cheaper~}$ than their current expenditure" (Project Document B, 2010). People were using kerosene lamps to light their home in the evenings before this project was commissioned. The population of the village comprised 1200 person with approximately 350 households and 50 shops. The village produced 1200 tons of Paddy every year. Therefore taking this into account the organization decided to install a low cost indigenous gasifier system with a capacity of $32 \mathrm{KW}$ using rice husk as the raw material. The plant initially provided electricity for lights in the homes and shops (approx. 300 connections) in the evening for 6 hours.

However the plant operation was further increased to accommodate some small industries 
and the heat of the plant was also used efficiently for processing some value added products.

Initially the project faced a few challenges such as increase in price of rice husk by the suppliers (with in the community) because of the opportunity cost, payment delay or default by some of the customers' (within the community) because there was no proper disconnecting mechanism for individual customers. However these issues were sorted out by installing an onsite dehusker to generate rice husk cheaply and starting a community led bill collection system to avoid delays in payment. The organization faced internal politics within communities when they were expanding into nearby villages, because of their initial link with in the community. In order to avoid this, the organization started to engage with the community as a whole from the beginning, without getting close to any section of the community. They also supported local schools and school children in various forms in order to build confidence among the local public and to remain neutral.

\subsection{Case C}

A privately owned textile processing unit which is using biomass based boiler to produce heat energy for the processes is Case C. The bioenergy plant was built as an alternative for diesel boiler, as the cost of diesel is increasing in India. The plant is situated in south Indian state of Tamilnadu, in a village very close to a nearby city with a population of 26,162 in 2011 . Distance of nearby residents from the plant is less than 100 metre from the factory. The size of the plant is $70 \mathrm{KW}$ thermal or $23 \mathrm{KW}$ equivalent of electricity (by considering 1:3 conversion ratio). They use coconut petiole as their fuel. The plant is operating continuously for 24 hours during normal working days except when it is under maintenance.

The nearby residents first complained about air emissions from the plant and the smoke and dust (or ashes) coming into their homes because of the plants emission. Some members of the community even lodged an informal complaint with the pollution control board (PCB). The PCB contacted the company and directed them to sort out the issues immediately. After thinking through different options, the company decided to change height and design of their exhaust chimney to address the issue. During this process the company had to go in for unplanned shutdown for a few days. After this incident the company decided to engage more closely with the nearby community. They also financially 
supported the community's plan to build a temple, which also helped them to create a strong link with the community.

\subsection{Case D}

A boiler with capacity of $500 \mathrm{KW}$ thermal ( $165 \mathrm{KW}$ equivalent of electricity, by considering 1:3 conversion ratio) is used in the privately owned rice mill to process paddy. The plant is located in an expanding town in south Indian state of Tamil Nadu with a population of 337923 in 2011. It utilizes heat energy from the plant both as steam and hot air. The plant is situated at the centre of the town with lots of shops and residences nearby. The plant used to operate for 2 eight hour shifts in a day for 6 days in a week and used rice husk as fuel. The rice husk was an easy source for them as it was a by product within their factory.

But the nearby residents were affected by air pollution of the plant and flying of the ash into their homes from the openly stored pile of ash. The residents directly contacted the company and lodged their complaint with them because the company's management had good connection with the local community and influence in the town. The company decided to use firewood as their raw material to avoid the problem and they sold their rice husk for other uses. They also built a closed storage for the ash. After making the changes they invited the nearby residents to the company, and showed and explained the changes they made and how this will address their concerns. After this the problem was resolved and the system has been running smoothly.

\section{Findings}

It is seen from the Cases C and D that if the community's concerns are not properly addressed then it can impact the social license to operate and even create legal and regulatory challenges for the companies. For example the Case $\mathrm{C}$, received a warning from the PCB due to complaints from the community. In Case B when they were planning to expand their operation to other sites they also faced community acceptance issues which created problems for them in venturing into new villages. In Case $A$ the project team worked very closely with the villagers from beginning to make it a success from community acceptance point of view. One of the possible reasons for them to proactively engage with the villagers can be the lessons learnt by some of the partners in the project by involvement 
in other small scale bioenergy projects previously. In Case B, C and D survival of the bioenergy plants were seriously threatened as a consequence of the community disapproval; through control of the necessary organisational sustainability conditions such as market acceptance, licence to operate etc. From this it can be drawn that in India, community's has significant influence over the survival of bioenergy projects. The level of influence can be even higher if local community holds other primary stakeholder roles with respect to the company such as customers or suppliers which is evident in Case A and B.

\section{Table 5: Community Concerns}

The community concerns found in the case studies are summed up in Table 5 . In Case $\mathrm{B}$ during the extension processes, part of community in the new village was concerned about credibility of the developer because of their initial association with one group of people in the first village. As cause of the issue was internal politics with in the community, developers decided to take a neutral stand. Local air pollution affecting nearby residents was one of the prime concerns in Case $C$ and D. In order to address this issue Case $C$ increased height of the chimney and Case D changed the feedstock they used. Inappropriate storage of by-products such as ash was also an important concern in Case D and the company then made changes in its by-products storage system. Cost of electricity was also raised as a concern by the community in Case B.

\section{Table 6: Factors Influencing the Community Acceptance}

Factors influencing the community's perception or acceptance in the cases studied are given in Table 6. Catering to the local energy need is identified as an important factor which influences bioenergy plants acceptance by the community. The community members can hold other roles linked to an organization such as customers, shareholders, employees, suppliers and etc which have influence over their acceptance and voice. The proximity to the residents becomes an important factor especially when the project can impact on the surroundings and health of those nearby residents. For example in Case $A$ and $B$ the communities did not lodge any environmental concerns as in Cases $C$ and $D$. Some of the differences between these two groups are discussed below. The business model of Case $A$ 
and $B$ is to supply electricity to the community where they were facing energy shortage, as compared to the captive power plant business model of Case C and D. In Case A and B, the community members also held other roles such as suppliers, customers and employees whereas in Case $C$ and $D$ this was not the case. Even their employees were not from within the nearby resident community. In Case $C$ and $D$, companies were in a close proximity to the residents who complained about the air pollution but this was not the case with other two cases.

The community's acceptance is influenced by other benefits provided for the community by the companies as in all the cases except in Case D. The companies provided some form of benefits to the community such as building a temple, providing support for local schools and irrigation systems. These initiatives have been undertaken either from beginning (Case $A$ ) or after the community issues were raised (Case $B$ and $C$ ), which helped them build a better relationship with the community. Opportunity provided to the local community to control the project was limited in most of the cases; however it seems to produce significant benefits. For example, in Case A teams were set up within the community to help in management of the plant. This gave the community added confidence and voice over the project, which in turn developed a feeling of being a part of it and they related more closely with the project when compared to other cases. Providing information about project is seen as an important factor in avoiding any misconceptions, to build confidence within the community and very importantly to scrutinize the even-handedness about the choices made. In Case D the company held information sharing events to inform the community about how they have addressed the issues raised. In Case A and B also it was the fundamental building block of the business model.

In Case A, B and D the companies developed close relationship with the community and maintained continuous communication with them from the beginning. This allowed easy engagement in both directions. In Case $C$ the company lacked proper public relation strategy. This led them to deal with the PCB rather than the community itself to address their concerns. This shows the importance of communication and relationship with the communities, which can enable the companies to interact with them regularly as it is a fundamental step to listen to their concerns. Trust on the company is an important aspect which influences how much the community believes their words, actions and intentions. In Case B, company faced challenges initially due to lack of trust by part of the community. In 
Case $\mathrm{C}$ the community had low confidence about the company due to which they directly complained to the PCB rather than to the company. In Case D the nearby residents lodged their concerns with the company directly due to their trust on them. Case A developed trusted relationship with the community through involvement of the community in the process from very initial stages. This highlights that communication and relationship building is one of the important instruments to develop trust.

\section{Discussion}

From the above case studies it is evident that in India, in addition to the necessary conditions such as biomass availability and appropriate technological solutions, community acceptance also has significant influence over sustainable bioenergy projects even if it is not in the same magnitude as mentioned in other cases from the developed countries (Plate et al., 2010; Upham \& Shackley, 2006; Upreti, 2004). This emphasises the significance of achieving community acceptance for bioenergy projects in India to be sustainable, which is an outside-in linkage for the business (Porter \& Kramer, 2006). These findings call for more attention from the practitioners regarding community acceptance of the projects.

The important concerns in the cases studied were local air pollution, inappropriate storage of the by-products and credibility of the developer. From the cases that have been examined it can be seen that concerns of the community were justifiable and mostly related to impact on health of the nearby residents and fear of potential discrimination against a particular group. All these concerns were also identified in other countries which are shown in the Table 2 developed using literature review. However the scope of the concerns is minimal in India when compared to those of the developed countries. One of the potential reasons for this varying degree of community concerns in different countries can be different socio-economic situations of the community which can indirectly influence the acceptance of the projects in a particular region such as income level, life style, employment rate, etc (Halder et al., 2013; Wegener \& Kelly, 2008). Therefore, these findings from the case studies can be seen as the very minimum requirement for bioenergy projects in India and other requirements of the community need to be further analyzed for the individual projects.

In one of the cases the main concern of the community (related to the market) was cost of electricity which as expected shows, an interconnection between the community 
acceptance and market acceptance when the community holds other stakeholder roles such as customers or suppliers. This interconnected influence between different types of social acceptance is high especially with in small scale bioenergy projects.

Factors that can influence the community's acceptance or perception of the project in India are identified in this study. Except, other stakeholder roles and proximity to the residents all other factors have been identified as influencing factors in the developed world as well. However the number of factors identified as influencers are less compared to the list of factors in Table 3 developed from the literature review. Proximity to the residents is identified as a community concern in the developed world. In the Indian context even when it is not categorically expressed by the community as concern, it still plays a role in influencing their perception of the project. Other stakeholder roles held by the community members is identified in this study as an influencing factor due to the small scale nature of the project, where they can be a significant customer or supplier and which may not be the case in medium or large scale plants.

These factors influencing the community's concerns can be categorized using the classification system of the overall renewable energy sector for the same purpose proposed by the Wüstenhagen et al. (2007). Local energy needs, benefits to the community, other stakeholder roles and proximity to the residents are some of the factors influencing distributional justice expectations of the community. The factors that influence procedural justice expectations of the community are control over the project, information availability and communication and relationship. Trust is another expectation of the community under the classification system, where the factor under this category is called with the same name. These influential factors and classification can help the practitioners to take necessary steps to cater to the different expectations within and of the community. If a company can do well in all of these influencing factors and address the reasonable concerns of the community, it should be successful in having a cooperative and satisfied community.

In order to achieve community acceptance, the key is to identify the specific community needs in addition to the above mentioned requirements, especially the needs that cannot be satisfied via other channels. Engaging with the community has been identified as the first step in order to recognise the community's needs (Harvey \& Brereton, 2005) and it will also increase awareness among the community, which in turn minimize community risk for the project (Blumer et al., 2013; Upreti \& van der Horst, 2004). Having 
good public relations strategy is the key for engagement (Cacciatore et al., 2012; Halder et al., 2013; Magar et al., 2011; Qu et al., 2012) ; it should involve continuous communication with the community and should develop a perception in the community that company is easily approachable. The engagement can be a reactive solution after a risk has risen (for example as in the case of Case $\mathrm{C}$ where they engaged only after it has been reported to the PCB) or else a proactive approach (as in Case A and B which avoided the potential threats and whereas reduced the risk in Case D). Both approaches have its cost and benefits associated with it. However certain degree of proactive engagement taking context, type of project, business model and other influencing variables mentioned above into account would be more beneficial. Further research is required to address how to engage with community effectively to attain community and social acceptance for bioenergy projects, especially in developing countries. Also, value of the research can be enhanced further by conducting a survey with more projects as this research was based on a few case studies.

\section{Conclusion}

Given the potential of small scale bioenergy in India and importance of local community perception for sustainable bioenergy projects in developed countries, this research investigated the role of community acceptance for sustainable small scale bioenergy projects in India through three research questions. In answering the first research question about influence of communities, it has been identified that communities have significant influence over sustainability of the bioenergy projects through case studies. Identification of the important concerns of communities related to the small scale bioenergy projects was the second research question. In the cases studied local air pollution, inappropriate storage of by-products and credibility of the developer were recognised as important concerns of the communities. In response to the third research question about factors that influences community acceptance of the bioenergy projects, these were local energy needs, benefits to the community, other stakeholder roles, proximity to the residents, control over the project, information availability, communication and relationship and trust. The important contributions of this work are twofold. Primarily, findings from the empirical study has contributed to new insights on concerns of the community and factors influencing the community's perception from developing countries and small scale sectors perspective. These findings are compared with the findings from the studies related to the 
developed countries in the literature in order to understand the similarity and differences. The findings were analyzed using appropriate theoretical perspectives and categorized to provide useful perceptions. Secondly, syntheses of the literature on community concerns and factors influencing the community acceptance have added to the understanding in the field. In addition to the theoretical advancements, bioenergy practitioners can benefit from the findings, which would help them to understand concerns of the community and factors that can shape the communities perception. This can in turn facilitate attainment of community acceptance, required for a sustainable project.

\section{References}

Alasti, E. (2011). Social Acceptance of Bioenergy in Europe. Master of Science in Environmental Management and Policy, IIIEE Publications, Lund University, LUND, Sweden. 
Blumer, Y. B., Stauffacher, M., Lang, D. J., Hayashi, K., \& Uchida, S. (2013). Non-technical success factors for bioenergy projects - Learning from a multiple case study in Japan. Energy Policy, 60(0), 386-395. doi: http://dx.doi.org/10.1016/i.enpol.2013.05.075

Buchholz, T., Rametsteiner, E., Volk, T. A., \& Luzadis, V. A. (2009). Multi Criteria Analysis for bioenergy systems assessments. Energy Policy, 37(2), 484-495.

Cacciatore, M. A., Binder, A. R., Scheufele, D. A., \& Shaw, B. R. (2012). Public attitudes toward biofuels: Effects of knowledge, political partisanship, and media use. Politics and the Life Sciences, 31(1), 36-51.

Camerata, T., \& Bansal, A. (2011). Future Potential of Biomass Energy in India. Bioenergy India, Jan to Mar

Central Electricity Authority. (2012). Power supply position Retrieved 24/02/2014, 2014, from http://www.cea.nic.in/welcome.htm

Cherni, J. A., Dyner, I., Henao, F., Jaramillo, P., Smith, R., \& Font, R. O. (2007). Energy supply for sustainable rural livelihoods. A multi-criteria decision-support system. Energy Policy, 35(3), 1493-1504.

Deloitte. (2013). Energy Access for the Poor. In I. 2013 (Ed.), Securing tomorrow's energy today: Policy \& Regulations. India.

Dockerty, T., Appleton, K., \& Lovett, A. (2012). Public opinion on energy crops in the landscape: considerations for the expansion of renewable energy from biomass.

Enerdata. (2013a). Share of renewables in primary consumption. Global Energy Statistical Yearbook 2013 Retrieved 24/02/2014, 2014, from http://yearbook.enerdata.net/\#renewable-data-in-world-primary-consumptionshares-by-region.html

Enerdata. (2013b). Total energy consumption. Global Energy Statistical Yearbook 2013 Retrieved 24/02/2014, 2014, from http://yearbook.enerdata.net/\#energyconsumption-data.html

Eswarlal, V. K., Dey, P. K., Budhwar, P., \& Shankar, R. (2011a). Analysis of interactions among variables of renewable energy projects: A case study on renewable energy project in India. Journal of scientific and industrial research, 70(8), 713-720.

Eswarlal, V. K., Dey, P. K., \& Shankar, R. (2011b). Enhanced renewable energy adoption for sustainable development in India: Interpretive structural modeling approach.

Fereday, J., \& Muir-Cochrane, E. (2008). Demonstrating rigor using thematic analysis: A hybrid approach of inductive and deductive coding and theme development. International Journal of Qualitative Methods, 5(1), 80-92.

Freeman, R. E. (1984). Strategic Management: A Stakeholder Approach Boston: Pitman.

Friedman, A. L., \& Miles, S. (2006). Stakeholders: theory and practice: Oxford University Press, USA.

Gallopín, G. (2003). A systems approach to sustainability and sustainable development. Chile: United Nations Publications.

Garvare, R., \& Johansson, P. (2010). Management for sustainability-a stakeholder theory. Total Quality Management \& Business Excellence, 21(7), 737-744.

Halder, P., Pietarinen, J., Havu-Nuutinen, S., Pelkonen, P., Chang, C.-Y., Prokop, P., \& Usak, M. (2013). Knowledge, Perceptions, and Attitudes as Determinants of Youths' Intentions to Use Bioenergy-A Cross-National Perspective. International Journal of Green Energy, 10(8), 797-813. 
Halder, P., Prokop, P., Chang, C.-Y., Usak, M., Pietarinen, J., Havu-Nuutinen, S., . . Cakir, M. (2012). International survey on bioenergy knowledge, perceptions, and attitudes among young citizens. Bioenergy Research, 5(1), 247-261.

Harrison, J. A., Von Maltitz, G., \& Tiwari, S. (2011). Developing a sustainability framework for assessing bioenergy projects. Bioenergy India Jan - Mar 2011.

Harvey, B., \& Brereton, D. (2005). Emerging models of community engagement in the Australian minerals industry. Paper presented at the United Nations engaging communities conference, Brisbane.

Hiremath, R. B., Kumar, B., Balachandra, P., \& Ravindranath, N. H. (2010). Bottom-up approach for decentralised energy planning: Case study of Tumkur district in India. Energy Policy, 38(2), 862-874.

Hiremath, R. B., Kumar, B., Balachandra, P., Ravindranath, N. H., \& Raghunandan, B. N. (2009). Decentralised renewable energy: Scope, relevance and applications in the Indian context. Energy for Sustainable Development, 13(1), 4-10.

Hooper, R. J., \& Li, J. (1996). Summary of the factors critical to the commercial application of bioenergy technologies. Biomass and Bioenergy, 11(6), 469-474.

IEA. (2002). Energy and Poverty World Energy Outlook (pp. 365-393). France: International Energy Agency (I.E.A.).

IEA, \& OECD. (2006). World Energy Outlook 2006. Paris: IEA \& OECD.

IEA, \& OECD. (2012). World Energy Outlook 2012. Paris, France: IEA.

Ivory, S., \& MacKay, B. (2012). Corporate Sustainability: a critical review. Paper presented at the BAM Conference 2012, Cardiff.

Jain, V., Sahni, P., Mohan, S., Iyer, S., Popli, K., \& Meshram, J. (2011). Bioenergy Road Map An Initiative by MNRE. Bioenergy India, JULY - SEPTEMBER \& OCTOBER - DECEMBER 2011.

Joffe, H., \& Yardley, L. (2004). Content and Thematic Analysis. London: Sage Publications Ltd.

Johansson, P. (2008). Implementing stakeholder management: a case study at a microenterprise. Measuring Business Excellence, 12(3), 33-41.

Khan, A. R. (2005). Beyond the Talk: Engaging Stakeholders in Bioenergy Development Bioenergy Issue: UNEP.

Kumar, B., Hiremath, R. B., Balachandra, P., \& Ravindranath, N. H. (2009). Bioenergy and food security: Indian context. Energy for Sustainable Development, 13(4), 265-270.

Lewandowski, I., \& Faaij, A. P. C. (2006). Steps towards the development of a certification system for sustainable bio-energy trade. Biomass and Bioenergy, 30(2), 83-104.

Magar, S. B., Pelkonen, P., Tahvanainen, L., Toivonen, R., \& Toppinen, A. (2011). Growing trade of bioenergy in the EU: Public acceptability, policy harmonization, European standards and certification needs. Biomass and Bioenergy, 35(8), 3318-3327.

Miles, M. B., \& Huberman, A. M. (1994). Qualitative data analysis: An expanded sourcebook: Sage Publications, Incorporated.

Mitchell, C. P. (2000). Development of decision support systems for bioenergy applications. Biomass and Bioenergy, 18(4), 265-278.

Painuly, J. P. (2001). Barriers to renewable energy penetration; a framework for analysis. Renewable Energy, 24(1), 73-89.

Peelle, E. (2000). Stakeholder views and concerns about bioenergy: organizational focus, driver issues and uncertainty. Paper presented at the Proceedings, Bioenergy.

Peelle, E. (2001). Bioenergy: Stakeholders see parts of the elephant. Oak Ridge National Laboratory, Oak Ridge, USA. 
Plate, R., Monroe, M., \& Oxarart, A. (2010). Public perceptions of using woody biomass as a renewable energy source. Journal of Extension, 48(3).

Porter, M. E., \& Kramer, M. R. (2006). Strategy and society. Harvard business review, 84(12), 78-92.

Qu, M., Ahponen, P., Tahvanainen, L., Gritten, D., Mola-Yudego, B., \& Pelkonen, P. (2012). Practices and perceptions on the development of forest bioenergy in China from participants in national forestry training courses. Biomass and Bioenergy, 40, 53-62.

Rao, K. U., \& Ravindranath, N. (2002). Policies to overcome barriers to the spread of bioenergy technologies in India. Energy for Sustainable Development, 6(3), 59-73.

Ravindranath, D., \& Rao, S. S. N. (2011). Bioenergy in India: Barriers and policy options Diffusion of renewable energy technologies (pp. 129). India: United Nations Development Programme.

Ravindranath, N., Somashekar, H., Dasappa, S., \& Reddy, J. C. N. (2004). Sustainable biomass power for rural India: Case study of biomass gasifier for village electrification. CURRENT SCIENCE, 87(7), 932-941.

Ravindranath, N. H., \& Balachandra, P. (2009). Sustainable bioenergy for India: Technical, economic and policy analysis. Energy, 34(8), 1003-1013.

Rohracher, H., Bogner, R., SpÃth, P., \& Faber, F. (2004). Improving the public perception of bioenergy in the EU Final Report within the project'Bioenergy's role in the EU Energy market: Directorate-General for Energy and Transport, European Commission.

Romijn, H., Raven, R., \& de Visser, I. (2010). Biomass energy experiments in rural India: Insights from learning-based development approaches and lessons for Strategic Niche Management. Environmental Science \& Policy, 13(4), 326-338.

Roos, A., Graham, R. L., Hektor, B., \& Rakos, C. (1999). Critical factors to bioenergy implementation. Biomass and Bioenergy, 17(2), 113-126.

Rösch, C., \& Kaltschmitt, M. (1999). Energy from biomass--do non-technical barriers prevent an increased use? Biomass and Bioenergy, 16(5), 347-356.

Shweta. (2012, 22/06/2012). MNRE report in Bioenergy Mission Retrieved 22/11/2012, 2012, from http://www.eai.in/club/users/Shweta/blogs/7498

Somashekhar, H., Dasappa, S., \& Ravindranath, N. (2000). Rural bioenergy centres based on biomass gasifiers for decentralized power generation: case study of two villages in southern India. Energy for Sustainable Development, 4(3), 55-63.

South Centre. (2008). The role of decentralized renewable energy technologies in adaptation to climate change in developing countries. Geneva, Switzerland: South Centre (S.C.).

Thomas, J., \& Harden, A. (2008). Methods for the thematic synthesis of qualitative research in systematic reviews. BMC Medical Research Methodology, 8(1), 45.

Thornley, P., Upham, P., Huang, Y., Rezvani, S., Brammer, J., \& Rogers, J. (2009). Integrated assessment of bioelectricity technology options. Energy Policy, 37(3), 890-903.

Upham, P. (2006). Bioenergy perceptions review: a summary of literature on UK public and stakeholder perceptions of bioenergy for heat and power. Stakeholder and Public Perceptions of 2030 Bioenergy Scenarios for Yorkshire and Humber - VOLUME 2 (slides and literature review). Tyndall Centre Manchester and Manchester Business School. Manchester.

Upham, P., \& Shackley, S. (2006). Stakeholder opinion of a proposed 21.5 MWe biomass gasifier in Winkleigh, Devon: Implications for bioenergy planning and policy. Journal of environmental policy and planning, 8(01), 45-66. 
Upreti, B. R. (2004). Conflict over biomass energy development in the United Kingdom: some observations and lessons from England and Wales. Energy Policy, 32(6), 785800.

Upreti, B. R., \& van der Horst, D. (2004). National renewable energy policy and local opposition in the UK: the failed development of a biomass electricity plant. Biomass and Bioenergy, 26(1), 61-69.

Voss, C., Tsikriktsis, N., \& Frohlich, M. (2002). Case research in operations management. International Journal of Operations \& Production Management, 22(2), 195-219.

Walter, G., \& Gutscher, H. (2011). Public acceptance of wind energy and bioenergy projects in the framework of distributive and procedural justice theories: Insights from Germany, Austria and Switzerland. Zürich The Advisory House.

Wegener, D., \& Kelly, J. (2008). Social Psychological Dimensions of Bioenergy Development and Public Acceptance. Bioenergy Research, 1(2), 107.

Wright, L. (2006). Worldwide commercial development of bioenergy with a focus on energy crop-based projects. Biomass and Bioenergy, 30(8-9), 706-714.

Wüstenhagen, R., Wolsink, M., \& Bürer, M. J. (2007). Social acceptance of renewable energy innovation: An introduction to the concept. Energy Policy, 35(5), 2683-2691. doi: http://dx.doi.org/10.1016/i.enpol.2006.12.001

Yin, R. K. (1994). The Case Study Research. Designing and Methods: London: sage. 